SAND99-0147

Unlimited Release

Printed February 1999

\title{
External Review for Sandia National Laboratory Microelectronics and Photonics Program 1998 Review
}

\author{
A. D. Romig \\ P. J. McWhorter \\ Microsystems Science, Technology and Components \\ Sandia National Laboratories \\ P.O. Box 5800 \\ Albuquerque, NM 87185-1078
}

\begin{abstract}
The US Department of Energy requires a periodic "Self Assessment" of Sandia's Microelectronics and Photonics Program. An external peer review of this program is held approximately every 18 months, and the report from the external review panel serves as the basis of our DOE "Self Assessment". The panel is comprised of leading experts in the fields of microelectronics, photonics, and microsystems from Universities, Industry, and Other Government Agencies. The panel reviewed the Microelectronics and Photonics Program on April 27-28, 1998, and this report presents their findings.
\end{abstract}




\section{DISCLAIMER}

This report was prepared as an account of work sponsored by an agency of the United States Government. Neither the United States Government nor any agency thereof, nor any of their employees, make any warranty, express or implied, or assumes any legal liability or responsibility for the accuracy, completeness, or usefulness of any information, apparatus, product, or process disclosed, or represents that its use would not infringe privately owned rights. Reference herein to any specific commercial product, process, or service by trade name, trademark, manufacturer, or otherwise does not necessarily constitute or imply its endorsement, recommendation, or favoring by the United States Government or any agency thereof. The views and opinions of authors expressed herein do not necessarily state or reflect those of the United States Government or any agency thereof. 


\section{DISCLAIMER}

Portions of this document may be illegible in electronic image products. Images are produced from the best available original document. 


\title{
External Review for Sandia National Laboratory Microelectronics and Photonics Program 1998 Review
}

\section{EXECUTIVE SUMMARY}

\author{
Strategic Technology and Business Issues
}

The committee regards Sandia's Microelectronics and Photonics Program as a vital and strategic resource for the nation. The Microsystems (MEMS) and Chem Lab Programs were assessed as unique and best-inclass for the development of significant application areas. They contribute directly to the Sandia mission and impact the development of new commercial areas. The continued development and integration of radiation hard silicon integrated circuits, micromechanical systems, sensors, and optical communications is essential to the national security mission.

A successful Sandia Microelectronics and Photonics Program is essential for achieving the DOE mission. Sandia continues to provide a critical service for the nation's national security, and also continues to develop leveraged partnerships with the nation's microelectronics infrastructure.

In this review, Sandia's vision and mission for microelectronics - as well as mission related applications were clearly articulated. The interfaces between the Sandia microelectronics technology development programs and the mission oriented engineering application programs were well developed. Technologies developed by the Microelectronics programs were aligned to application objectives. The committee was particularly pleased to see this connectivity and to hear presentations by the customers of the Microelectronics Programs.

The committee's consensus review includes these concepts, directions and recommendations.

Sandia needs to continue to lead technology development in radiation hard microelectronics, e.g., process and device development. Sandia should develop a strategy to scale production of radiation hard integrated circuits to match changing mission needs. This is especially important as commercial interest in this technology remains questionable.

Sandia must execute a strategy to guarantee the surety of microelectronic system replacements for safe status, arming, and fusing of weapons over their expected lifetime. The strategy should be further integrated, and must address the development of technologies that improve reliability.

At times the Sandia mission is supported by the commercialization of Sandia technologies. In some cases, e.g., MEMS, high quality partnerships have been established. The committee believes that a systematic approach to developing these partnerships, for example early involvement in technology development, is important to achieving the Sandia mission.

Sandia has a unique scientific and technical capability to address grand challenges and the panel committee urges the management to continue to define other grand challenge problems within the context of the Sandia mission. 
- $\quad$ The committee would like to see a strategy by focus area, e.g., Chem Lab, MEMS, radiation hard microsystems, compound semiconductors, that includes interaction and leverage with the infrastructure, i.e., the industry, other government agencies, and universities. In particular, benchmarking with elements of the appropriate infrastructure is desirable.

Sandia has the opportunity to work with universities and industry to lead the development of integrated CAD tools for microsystems that encompass several physical domains.

- Sandia has a distinguished history in advanced microsystems. The committee strongly supports the continued emphasis on discovery research in this area and the incubation to new applications.

The committee would like to have the opportunity to review the other leading-edge research in the next review. This includes work in compound semiconductors, dense packaging, modeling, and reliability. The committee would also like a review of the research methodologies and their application / development interfaces.

\section{ASSESSMENT PERFORMANCE MEASURES}

A. Quality of Science and Engineering

Programs that were briefed in microsystems are outstanding. Specific programs such as MEMS and Chem Lab are unambiguously world leaders. The Sandia solution to the successful processing of both the micromechanical and the electronic control and sensor elements of MEMS devices is an outstanding achievement.

- $\quad$ The portion of the Photonic integrated circuits program presented is believed to be excellent and the committee looks forward to reviewing the complementary programs in this area at the next review. The use of VCELS's to monitor the position of mechanical components in stronglinks and detonator surety devices is an innovative approach to apply Sandia's photonics expertise to mission critical systems. Refinement of the criteria for the applications of Sandia's photonic integrated circuit technology again demonstrated innovative approaches to national security problems.

- The committee is concerned about the survivability of the radiation hard program due to the . instability of the commercial sector. Sandia is commended for quality of its efforts to sustain the radiation hard program through partnering with industry. This committee has concerns about Sandia's ability to maintain a viable and enduring leadership for a radiation-hard capability under current funding conditions.

- $\quad$ The demonstrated systems engineering approaches for applications to surety programs are novel and outstanding.

\section{B. Program Performance, Management, and Planning}

- The program planning is excellent-to-outstanding and demonstrably connected to systems applications.

- The Roadmap processes are active and internally coordinated with the customers (US Government stockpile)

- A key for further improvement is to network and leverage their competitors and suppliers in all specialty areas, e.g., MEMS, RDA Hard, .... 
- The need to rationalize and priortize the balance of effort between stockpile stewardship efforts and other national interest activities is essential.

- Substantial improvements in the regard for MDL, on the part of its Defense Programs customer is noted and deserves acknowledgement from SNL upper management.

- The committee believes that the Sandia Microelectronics and Photonics Program is conducting discovery research and suggests that it should continue to devote about $10-15 \%$ of its resources to exploratory efforts. Examples include remote interrogation of Chem Lab instruments, cost effective design and production of microsystems that are being developed, development of high productivity integrated microsystem design tools,...

C. Relevance to National Needs and Agency Mission

- The overall relevance of the programs reviewed to needs and the DP mission is outstanding. Suggested areas for future focus are as follows:

- Sandia must meet its mission by further development of radiation-hard capability.

- The Chem Lab program is an excellent example of technology development applicable to the national interest, e.g., use in anti-terrorist technology

- The opportunity to assess national issues beyond the current horizon such as diminishing natural resources; oil/energy in particular, and advanced photovoltaics should be revisited.

- The committee recommends a coordinating effort with other relevant agencies who are driving programs in the national interest. E.g. define possible roles vis a via the implications of proliferation of nuclear capabilities, environment, etc.

- Regarding emphasis and focus - while operating under the assumption of a constrained budget - it is necessary to complete programs while adding new ones to maintain vitality. One way to assess this need for vitality would be for the committee to see a review and plan for program/project completion and program prioritization and initiation.

D. Performance in the Operation of a Major Research Facility

Sandia has done an excellent job operating the MDL in a very challenging environment. With industry nearing abandonment of rad-hard integrated circuit development, effective operation of the MDI, becomes even more important. Maintaining the appropriate evolution of equipment and processing technology with respect to industry is one of the biggest challenges. Specific recommendations of the committee are as follows:

- Need to find partners/customers for MDL, e.g., commercial users.

- Need a plan to incorporate donated industry equipment, e.g., conversion from 6" to 8" wafer sizes.

- More generally, MDL needs a facility upgrade plan so that semiconductor industry can support development. This should be expressed in terms of technology node progression requirements. 


\section{SPECIFIC PROGRAMS REVIEWED}

\section{A. Defense Program's Drivers for Electronics Science, and Technology Council-Ron Andreas}

Sandia's Defense Programs provide the primary drivers for the Microelectronics and Photonics Program. Key needs of the Defense Program Sector include stockpile refurbishment, nuclear safety and security improvements, more affordable parts, and embedded surveillance. These needs require the use of existing, and the development of new microtechnologies. A set of roadmaps have been generated which show the insertion of microelectronics and microtechnologies into key weapon systems. Unfortunately this presentation correctly revealed the primitive level of understanding of the predictive aging and 'soft failure' mode of the electronic and most other heterogeneous materials' components in the stockpile. Time tables for remanufacturing or refurbishment - other than those dictated by obvious considerations like tritium half life are not solidly based. This is an area that deserves enhanced attention among MDL researchers.

\section{B. Rad Hard Microelectronics}

Special-purpose, radiation-hardened microelectronics are critical to Defense systems because off-the-shelf, commercial integrated circuits will not meet radiation requirements. Sandia's microelectronics strategy is to buy commercial parts when they meet mission needs, and to maintain in-house research, technology, and product capabilities so that technologies can be transferred to industrial partners for manufacturing, and as a last resort, to supply product to systems customers using the MDL facilities. The following talks describe the activities at Sandia's Microelectronics Development Laboratory that support these critical defense microelectronics needs.

\section{Product Drivers - Mike Knoll}

The needs of system customers drive Sandia's microelectronics capabilities. Sandia microelectronics' customers include the Nuclear Weapons program (stockpile upgrades as well as advanced development programs), nuclear non-proliferation programs (satellite payloads), and low-volume custom chips for other government agencies. Sandia Microelectronics will provide over 20 different chip types to systems customers in FY98 at volumes too low to be of commercial interest. These chip sets include 17 different digital circuit types, 4 custom analog circuit types, and 3 different types of rad-hard non-volatile memories.

\section{Technology Realization - Harry Weaver}

Sandia's Microelectronics Development Laboratory supports three different technology generations in a single facility and supports seven different custom, low-volume technologies. These include $1.25-\mu \mathrm{m}$ lithography for analog integrated circuits, micro-electro-mechanical systems and smart sensors, a $0.5-\mu \mathrm{m}$ baseline digital rad-hard complementary metal-oxide-semiconductor CMOS, and a developmental $0.35-\mu \mathrm{m}$ digital technology which will support migration of rad-hard technologies to higher performance and higher integration levels. To support Sandia's strategy of technology transfer where possible, and low-volume production as a last resort, industry-standard equipment and materials are used to maintain and develop these technologies. By sustaining and exercising its microelectronics capabilities, Sandia is able to maintain and advance the technology base for radiation-hardened microelectronics and to provide systems customers with custom radiation-hardened integrated circuits at volumes too low to be of commercial interest or in technologies not supported by commercial vendors of rad-hard circuits.

\section{Microsystems}

\section{Defense Drivers for Microsystems - Michael Callahan}

There are three principal nuclear weapon issues: 1) Are the weapons safe, secure and reliable, 2) Will they meet the required mission lifetime? and 3) could we respond to new threats if we had to? Microsystems offer the promise of significantly impacting these issues by enabling rugged, modular, multi-application 
subsystems. Roadmaps have been generated which illustrate the plan for incorporation of microsystems into critical weapon systems. One question is, have these been vetted sufficiently with the DP customer?

\section{Micro-Strong Link - Steve Rodgers}

Strong links are important safety components that insure weapons will not detonate in accidents. A number of potential advantages could be realized by achieving strong links in MEMS technologies. Proof-ofconcept micromachine strong links have been demonstrated, comprised of twenty four-bit mechanical discriminators coupled to positionable. This demonstration system includes mechanical elements as small as one micron across. This was an excellent example of the potential for MEMS technology and illustrated level of customer responsiveness.

\section{Micro-Inertial Measurement Units - Jim Smith}

Sandia defense missions require inertial measurement units for a variety of applications ranging from shock sensors to inertial navigation. Applications exist for $G$ switches for fuzing, environmental sensing for safety of weapons, and more precise devices for inertial navigation. Micromachined inertial measurement units are attractive for these applications because of their low cost, small size, reliability and performance. Sandia is developing unique integrated MEMS/CMOS technologies which enable the realization of complete inertial measurement systems on a chip. Sandia is presently working to transition these devices from laboratory prototypes to qualified products.

\section{Chem Lab on a Chip - Gregg Frye-Mason}

A significant need exists for an affordable small device capable of detecting a wide range of chemical and biological agents. Applications exist in non-proliferation, counter-terrorism, mine detection, and stockpile stewardship. Based on these needs, Sandia is pursuing the development of a Chem Lab on a Chip. This device will integrate preconcentrators, separation channels, detectors, pumps and valves on a single chip, enabling the detection of a broad spectrum of chemical and biological agents. Individual components of the Chem Lab on a Chip have been demonstrated, including micro-preconcentrators, detectors, and GC columns. Ongoing work will integrate these elements onto a single chip. This project represents something of an experiment with a larger scale and fully coordinated LDRD project. If successful, it could change the way LDRD (a $\$ 70 \mathrm{M}$ program annually at SNL) is managed. It requires and deserves careful scrutiny.

\section{E. Opto Electronics for National Security}

The crowded interior volumes and limited power budget of existing nuclear weapons mandate that any upgrades for enhanced surety and embedded weapon surveillance must be compact and highly efficient. Sandia's Center for Compound-Semiconductor Science and Technology has been developing efficient and compact optical technologies and components with their associated packaging schemes to meet these unique weapon requirements.

\section{VCSEL Weapon Monitors - Mial Warren}

Sandia pioneered the development of high-efficiency ( $>50 \%$ electrical-to-optical) Vertical Cavity, SurfaceEmitting Lasers (VCSELs) through fundamental scientific investigations and applied material science. Sandia is applying these high-efficiency, compact VCSELs to monitoring and controlling weapon-safing subsystems. This was the weakest and least compelling of the projects or technologies that we saw. We hope that there are better uses for VCSELS in meeting the SNL mission.

\section{Photonic Integrated Circuits for National Security Applications - Charles Sullivan}

Photonic Integrated Circuits (PICs) are monolithic integrated microsystems that maximize functionality in minimum volumes through the use of photons rather than electrons for specific functions. Four prototype 
applications of PICs for national security will be described: 1 . An optically based, trajectory sensing safety subsystem on a chip; 2 . PIC alternatives to high-speed logic for encryption of light-wave signals for secure communication, 3. a solid-state optical steering systems for laser-based nanosatellite crosslinks for real time monitoring and global communication of weapons of mass destruction; and 4 . high-sensitivity waveguide modulators for lower power, improved noise, reduced weight of satellite based if phased-array signal and imaging systems

\section{F. Technology Migration - Harry Weaver}

Sandia has a strategy for evolving its integrated circuit (IC) technologies to fulfill its mission as the government contingency fabrication facility and acquire modern equipment within the constraint of limited capitol equipment budgets. Under this strategy Sandia develops hardening techniques for IC technologies that pace the commercial cutting edge within one or two generations. Sandia establishes significant partnerships under which they exchange engineering and scientific data on equipment performance for equity in the equipment itself. They advanced from $1.25 \mu \mathrm{m}$ to $0.5 \mu \mathrm{m}$ in 1995 and within a year will be fabricating $0.35 \mu \mathrm{m}$ IC. Approximately $80 \%$ of the new equipment has been obtained under the equipment partnerships. They will also change from 6 inch diameter wafers to 8 inch. But this change is dictated by the availability of 6 inch wafers rather than performance issues. Under the present strategy they anticipate moving to $0.2 \mu \mathrm{m}$ in approximately 6 years. By maintaining a fixed relationship to the commercial industry's cutting edge technology and continuing to interact with equipment vendors Sandia expects to establish a steady advance for radiation hardened IC.

\section{SUMMARY}

The committee regards Sandia's Microelectronics and Photonics Program as a vital and strategic resource for the nation. The Microsystems (MEMS) and Chem Lab programs were assessed as unique and best-inclass for the development of significant application areas. They contribute directly to the Sandia mission and impact the development of new commercial areas. The continued development and integration of Radiation hard silicon integrated circuits, micromechanical systems, sensors, and optical communications is essential to the national security mission.

The quality of the programs is excellent to outstanding overall. MEMS and Chem Lab activities are examples of outstanding programs. The committee was pleased to see the relationship of the microelectronics development programs to applications in the mission. In a future review the committee would like to see Sandia's research programs and a vision for connectivity to potential national security needs. (This review may be based on analysis and assumptions about the strategic needs of the nation.) In summary, the Microelectronics and Photonics capability affords Sandia the opportunity to deliver exceptional service in the national interest across broad technology areas.

The presentations were excellent and well integrated. We received ample pre-reading materials, expectations were well set and the documents were high quality. The committee was provided an agenda with sufficient time among us and some selected one-on-one time with the researchers. The composition of the committee held representation from industry, universities and government. Committee contributions were well balanced and worked as a team.

However, the committee was disappointed that no member of Sandia executive management was able to be present for the readout and final debriefing. (A late, higher priority conflict developed.) The members of the EST Program and the committee put substantial effort into the review but a written report like this one is not a substitute for direct feedback in helping SNL leadership assess the value of these programs 
Dr. Arpad Bergh

Optoelectronics Industry Development Association

2010 Massachusetts Avenue, NW

Suite 200

Washington, DC 20036-1023

Dr. Jack C. Boudreaux

NIST/ATP

Administration Room A231

Gaithersburg, Maryland 20899

Dr. John R Carruthers

Intel Corporation

5200 NE Elam Young Parkway RA1-301

Dr. Ralph K. Cavin

Semiconductor Research Corporation

P. O. Box 12053

RTP, North Carolina, 27709

Dr. Paul Fleury, Dean

University of New Mexico

Farris Engineering Center

Room 107

Dr. Ross A. Lemons

Materials Science \& Technology Division

Los Alamos National Laboratory

P. O. Box $1663 \quad$ M.S. G754

Los Alamos, NM 87545

Dr. Zachary J. Lemnios

MIT Lincoln Labs

244 Wood St., MS C351

Lexington, Mass. 02173

Mr. James B. Owens

2708 Westlake Dr.

Austin, TX 78746

Dr. Tom Seidel, Panel Chairman

GENUS

1139 Karlstad Dr.

Sunnyvale, CA 94089

Dr. Robert J. Trew

U.S. Department of Defense

ODDRE(R)

4015 Wilson Blvd., Suite 209

Arlington, VA 22203 
DISTRIBUTION:

1 MS 9018 Central Technical Files, 8940-2

2 MS 0899 Technical Library, 4916

1 MS 0619 Review \& Approval Desk, 15102

For DOE/OSTI 